\title{
Lançamento de livro no III Colóquio Espaço e Economia
}

\section{Roberto Moraes Pessanha}

\section{(2) OpenEdition}

1 Journals

\section{Edição electrónica}

URL: http://journals.openedition.org/espacoeconomia/6349

DOI: $10.4000 /$ espacoeconomia.6349

ISSN: 2317-7837

\section{Editora}

Núcleo de Pesquisa Espaço \& Economia

Refêrencia eletrónica

Roberto Moraes Pessanha, «Lançamento de livro no III Colóquio Espaço e Economia ", Espaço e Economia [Online], 14 | 2019, posto online no dia 12 agosto 2019, consultado o 04 setembro 2019 URL : http://journals.openedition.org/espacoeconomia/6349; DOI : 10.4000/espacoeconomia.6349

Este documento foi criado de forma automática no dia 4 Setembro 2019

(C) NUPEE 


\section{Lançamento de livro no III Colóquio Espaço e Economia}

Roberto Moraes Pessanha

\section{Conexão}

1 Editora e Livraria Consequência

2 Junho de 2019

3 http://livrariaconsequencia.com.br/

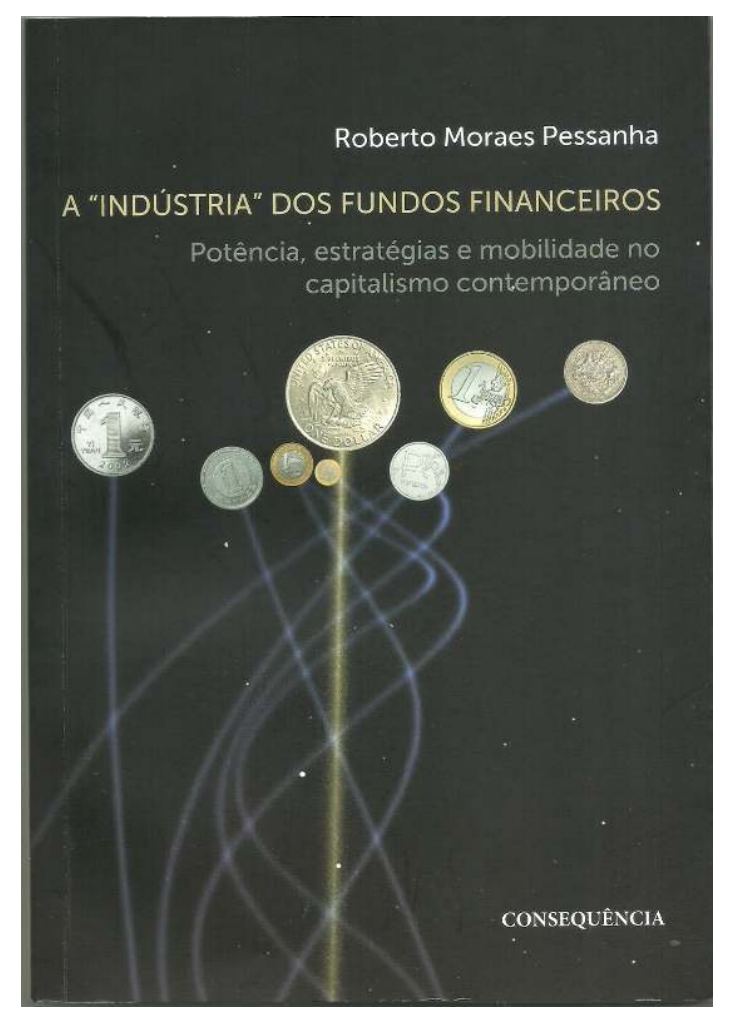




\section{Apresentação}

4 A busca incessante por informações sobre os percursos dos capitais financeiros e os seus movimentos de alocação em empreendimentos pelas diferentes frações de capitais e conglomerados empresariais, em todo o mundo, é o que permitiu a produção deste livro. Tarefa difićlima, por se tratar de um setor da economia que "opta por se manter hermético e invisível”, utilizando-se de inúmeros artifícios para ocultar os fatos e processos engendrados na teia de relações obscuras de transferências e movimentações de recursos. Difícil também pelas transferências via paraísos fiscais, que assim contornam as restrições de movimentação de capital e de investimentos que são contabilizados em cada país ${ }^{1}$.

5 Nos últimos anos, acompanhamos o empenho de Roberto Moraes em desvelar as teias e redes tecidas pelo capital, na busca voraz de maior rentabilidade. Esse esforço nos faz lembrar os percursos de análise propostos por Henry Lefebvre, atento à necessidade de considerar, nos processos rastreados, os fatos menos visíveis e os sentidos menos palpáveis, perceptíveis, muitas vezes, apenas nos seus interstícios. Roberto, metodologicamente, insistiu justamente no desvendamento dos percursos do capital nos quais se aninham suas estratégias e movimentos quase invisíveis, praticamente subsumidos em redes e sistemas que não revelam suas funcionalidades e interesses mais profundos.

6 A pesquisa desenvolvida pelo autor revela também uma experiência de investigação rara no contexto acadêmico, que em geral tem sua atividade desenvolvida por meio de projetos de investigação ancorados na previsão de fases e procedimentos que se sucedem por anos a fio, antes que se tenha um resultado. 0 processo de produção do conhecimento de Roberto Moraes não é totalmente diferente, já que sua investigação sobre o tema, a rigor, começou no ano de 2012, quando, iniciando seu doutoramento, pouco a pouco foi desenvolvendo sua pesquisa sobre os capitais que cercam a produção do petróleo e as redes logísticas de circulação desta fração do capital. Mas, nesse processo, ressalta-se, como um traço peculiar, a forma como as fases e procedimentos formalmente previstos da pesquisa são atravessados por um peculiar dinamismo de atenção cotidiana ao emaranhado de informações a partir das quais alimenta seu diálogo em vários fóruns $\mathrm{e}$ redes sociais.

7 Essa forma dinâmica de investigação decorre do fato de que Roberto Moraes é coordenador de um blog acadêmico, em que há mais de 10 anos analisa cada movimento do capital produtivo e rentista na esfera da economia do petróleo no Brasil e no mundo. Desde os primeiros movimentos de mudanças sócio-espaciais na Região Norte do Estado do Rio de Janeiro, decorrentes desse setor da economia, suas pesquisas buscam identificar cada sujeito social ou agente econômico que interfere no processo. Assim, desenvolveu uma capacidade impar de rastrear os caminhos percorridos pelo capital, localizar suas origens e situá-lo dentro de cada contexto, tarefa que consideramos extremamente árdua e que toma de 10 a 12 horas por dia do autor, entre aulas, palestras e, sobretudo, percorrendo uma vasta literatura sobre o tema e investigando sites corporativos e institucionais em todos os cantos do mundo. No segundo semestre de 2016, em viagem à Europa, dedicou-se a visitar mais de 5 países para conhecer áreas portuárias especializadas em circulação do petróleo e produtos petroquímicos, bem como as teias 
globais dos conglomerados com atuação no Brasil, por meio de fundos ou de investimentos diretos.

É importante ressaltar, também, que no atual estágio de desenvolvimento das forças produtivas, em que o capital adquire imensa mobilidade espacial, a busca pela identificação dos empreendimentos aproxima Roberto Moraes da análise sobre as interferências e a localização dos investimentos no território. Por isso, a sua aproximação com o conceito de circuito espacial da produção. Roberto destaca que, mesmo em ambientes de intensa fluidez do capital e de financeirização, que viabilizam, inclusive, inúmeras rendas classificadas derivadas, deve-se evitar a dissociação entre capital produtivo e capital financeiro, já que não se pode desconsiderar a importância da conjugação entre os novos e velhos processos de acumulação do capital na atual fase acumulativa. Com isso, evidencia-se também a "relação entre o movimento de produção do valor e de produção do espaço".

9 Esses aspectos fazem deste livro uma inestimável contribuição ao conhecimento sobre a nova configuração e fluxos dos capitais, destacando-se o conhecimento tanto das frações de capitais que ganham expressão na econômica contemporânea, quanto da dimensão da localização e dos efeitos territoriais de todos os processos de acumulação contemporânea. A relação espaço e economia na produção do espaço social, que é o objeto de estudo de um dos grupos de pesquisa em que Roberto Moraes atua, não poderia ser melhor apresentada em toda a sua complexidade. Temos, portanto, um livro que associa de forma inovadora a produção do espaço social e a economia política.

É importante observar que a investigação de Roberto Moraes se aproxima das pesquisas realizadas pelo Professor Ladislau Dowbor, sintetizadas no excelente livro "A era do capital improdutivo: por que oito famílias têm mais riqueza do que a metade da população do mundo?", lançado no ano de 2017. No mesmo sentido em que Dowbor revela como os 737 conglomerados empresariais no mundo (top-holders) "dominam $80 \%$ do valor de todas as empresas transnacionais", Roberto nos oferece um quadro geral sobre os fundos de investimentos, bem como analisa seu papel na produção de desigualdades sociais, em todo o mundo e, em particular, no Brasil.

11 Por fim, estou seguro de que este livro de Roberto Moraes, A relação entre o movimento de produção do valor e de produção do espaço, é um trabalho que mostra todo o potencial intelectual do autor, oferecendo-nos uma reflexão que faz avançar a sua já destacada contribuição acerca da ação da fração do capital relacionada ao petróleo, agora espraiada para outro campo importante do conhecimento que são os fundos de investimentos e suas ações em um mundo globalizado. Diante disso, faço minhas as suas palavras ao advertir que "é preciso ir além da constatação geral sobre a financeirização buscando entender as entranhas e estratégias dessa transformação do capitalismo". Roberto cumpriu plenamente seus objetivos, e a academia e as lutas sociais ganham muito com isso. Rio de Janeiro, outono de 2019.

Floriano José Godinho de Oliveira

14 Professor Associado da UERJ e Coordenador do Programa de Pós-Graduação em Políticas Públicas e Formação Humana - PPFH 


\section{NOTAS}

1. Roberto Moraes acompanhou e colaborou com o esforço de Nelson Mabucanhahne na produção de sua tese de doutoramento no PPFH, cujo tema era os IDE dos países que compõem os BRICS em Moçambique, e essa foi uma importante experiência em que ambos constataram a imensa dificuldade de realizar esse rastreamento dos capitais aplicados em cada país.

\section{AUTOR}

\section{ROBERTO MORAES PESSANHA}

Professor e pesquisador do IFF

robertomoraespessanha@gmail.com 